\title{
Coronary Vasodilatory Action of Elgodipine in Coronary Artery Disease
}

\author{
Harry Suryapranata, MD, PhD, Arthur Maas, MD, Donald C. MacLeod, MB, ChB, MRCP, \\ Pim J. de Feyter, MD, PhD, Pieter D. Verdouw, PhD, and Patrick W. Serruys, MD, PhD
}

\begin{abstract}
The effects of intravenous elgodipine, a new second-generation dihydropyridine calcium antagonist, on hemodynamics and coronary artery diameter were investigated in 15 patients undorgoing cardiac catheterization for suspected coronary artery disease. Despite a significant decrease in systemic blood pressure, elgodipine infused at a rate of $1.5 \mu \mathrm{g} / \mathrm{kg} / \mathrm{min}$ over a period of $10 \mathrm{minutes}$ did not affect heart rate and left ventricular end-diastolic pressure. The contractle responses during isovolumic contraction showed a slight but significant increase in maximum velocity (56 \pm 10 to 60 \pm 10 seconds $^{-1}$; $<<0.005$ ), whereas the time constant of early relaxation was shortened from $49 \pm$ 11 to $44 \pm 9 \mathrm{~ms}(\mathrm{p}<0.05)$. Coronary sinus and great cardiac vein flow increased significantly by 15 and 26\%, respectively. As mean aortic pressure decreased, a significant decrease in coronary sinus $(-27 \%)$ and great cardlac vein $(-28 \%)$ resistance was observed, while the calculated myocardial oxygen consumption remained unchanged. In all, 69 coronary segments (including 13 stenotic segments) were analyzed quantitatively using computer-assisted quantitative coronary angiography. A significant increase in mean coronary artery diameter $(2.27 \pm 0.53$ to $2.48 \pm 0.53 \mathrm{~mm}$; $<0.000001)$, as well as in obstruction diameter, (1.08 \pm 0.29 to $1.36 \pm 0.32 \mathrm{~mm}$; $<0.02)$, was observed. The results demonstrate that elgodipine, in the route and dose described, induces significant vasodilatation of both coronary resistance and epicardial conductance vessels, without adverse effects on heart rate, myocardial oxysen demand and contractile indexes.
\end{abstract}

(Am J Cardiol 1992;69:1171-1177)

From the Thoraxcenter, Rotterdam, the Netherlands. This work was supported by a grant from Instituto de Investigacion y Desarrollo Quimico Biologico S.A. and Laboratorios Delagrange, Madrid, Spain. Manuscript received August 26, 1991; revised manuscript received and accepted January 2, 1992.

Address for reprints: Harry Suryapranata, MD, PhD, Department of Cardiology, Hospital de Weezenlanden, Groot Wezenland 20, 8011 JW Zwolle, the Netherlands.

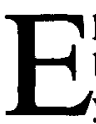
lgodipine (isopropyl (2-(N-methyl-N-(4-fluorobenzyl)-amine)-ethyl, 2,6-dimethyl-4-(2',3'-methylenedioxypheynl)-1,4-dihydropyridine-3,5-dicarboxylate, monohydrochloride) is a newly synthesized drug with calcium entry blocking properties belonging to the second generation of the phenyldihydropyridine group. ${ }^{1,2}$ In vitro studies have shown that the drug appears to be 100 -fold more potent in inducing vasodilatation than in causing negative inotropic effects ${ }^{1}$ and that when comparing different vascular beds, the most pronounced vasodilatory effect was in the coronary vasculature. ${ }^{3}$ This relative selectivity of elgodipine for the coronary vascular bed may be of particular significance in patients with coronary artery disease where an imbalance in myocardial oxygen supply and demand is caused by decrease in the coronary artery luminal diameter. Animal studies 3,4 have demonstrated that elgodipine is a potent vasodilator, decreasing blood pressure and total peripheral resistance, and increasing cardiac output and coronary blood flow dose-dependently, with little effect on heart rate. The potency of elgodipine in reducing systemic vascular resistance is slightly less than that of nifedipine, nisoldipine and nimodipine, but considerably greater (10- to 50 -fold) than that of bepridil, nicorandil and pimobendan. ${ }^{3}$ These effects of elgodipine on systemic and coronary hemodynamics have yet to be evaluated in patients with coronary artery disease. The present study investigates the effects of intravenous elgodipine on coronary and left ventricular hemodynamics, and assesses quantitatively the vasodilatory action of elgodipine on both stenotic and nonstenotic coronary arteries, using computer-assisted quantitative coronary angiography.

\section{METHODS}

Patients: The study comprised 15 patients (12 men and 3 women, mean age 57 years, range 40 to 69) who underwent cardiac catheterization for the investigation of suspected coronary artery disease. All patients were in sinus rhythm with no signs of cardiac failure and gave informed consent to participate in the study. $\mathrm{Pa}$ tients with unstable angina and acute myocardial infarction were excluded from the study. Clinical and angiographic data are listed in Table I.

Protocol: All medication was discontinued $\geq 48$ hours before the study. Cardiac catheterization was performed through the femoral artery and vein. Patients fasted and were not given premedication. No drug (other than $50 \mathrm{mg}$ of intravenous heparin) was administered during the study. After a thermodilution flow catheter was inserted in the coronary sinus and great cardiac vein, angiography of the right and left coronary artery 


\begin{tabular}{|c|c|c|c|c|c|c|c|}
\hline \multirow[b]{2}{*}{ Pt. } & \multirow{2}{*}{$\begin{array}{c}\text { Age }(y r) \\
\& \text { Sex }\end{array}$} & \multirow[b]{2}{*}{ NYHA } & \multirow[b]{2}{*}{ PMI } & \multirow{2}{*}{$\begin{array}{l}\mathrm{EF} \\
(\%)\end{array}$} & \multicolumn{3}{|c|}{$\begin{array}{l}\text { Coronary Artery } \\
\text { Narrowed }>50 \% \\
\text { in Diameter }\end{array}$} \\
\hline & & & & & LAD & LC & Right \\
\hline 1 & $43 \mathrm{~F}$ & 11 & 0 & 70 & 0 & 0 & + \\
\hline 2 & $66 \mathrm{M}$ & III & Anterior & 49 & + & + & + \\
\hline 3 & $68 \mathrm{M}$ & II & 0 & 50 & + & + & + \\
\hline 4 & $64 M$ & I & Inferior & 11 & + & 0 & + \\
\hline 5 & $55 \mathrm{M}$ & $\|$ & 0 & 62 & 0 & + & 0 \\
\hline 6 & $63 M$ & $\|$ & 0 & 77 & 0 & + & + \\
\hline 7 & $40 M$ & II & Anterior & 67 & + & 0 & 0 \\
\hline 8 & $44 \mathrm{M}$ & II & Anterior & - & + & 0 & 0 \\
\hline 9 & $60 M$ & II & Inferior & - & + & + & + \\
\hline 10 & $59 M$ & II & Anterior & 62 & + & 0 & 0 \\
\hline 11 & $51 \mathrm{~F}$ & $\|$ & 0 & 65 & 0 & 0 & 0 \\
\hline 12 & $64 M$ & II & Inferior & 66 & + & + & + \\
\hline 13 & $69 \mathrm{~F}$ & II & 0 & 64 & + & 0 & 0 \\
\hline 14 & $44 M$ & ॥ & Inferior & 55 & + & + & + \\
\hline 15 & $62 \mathrm{M}$ & II & Anterolateral & 71 & 0 & + & 0 \\
\hline
\end{tabular}

was performed in standard views including cranial and caudal angulations. The geometry of the x-ray gantry, and the kilovolts and milliamperes of the x-ray generator were obtained and recorded on-line for each angiogram. A dual-tip micromanometer catheter was then positioned in the left ventricle. Ten minutes after catheter instrumentation, baseline left ventricular and aortic pressures, pressure-derived indexes of isovolumic contraction and relaxation, and thermodilution coronary sinus and great cardiac vein flows were measured on-line at spontaneous heart rate. Oxygen saturations were ob- tained simultaneously from the aorta, coronary sinus and great cardiac vein. Elgodipine was then administered intravenously at a rate of $1.5 \mu \mathrm{g} / \mathrm{kg} / \mathrm{min}$ over a period of 10 minutes, and all measurements were repeated at 5,10, 20 and 30 minutes. Angiography of the left coronary artery was repeated at 10 and 30 minutes in all projections, corresponding to those used during baseline angiography. All angiograms were obtained using the Judkins technique and recorded on Kodak 35 $\mathrm{mm}$ cincfilm at a rate of 25 frames/second. Nonionic contrast medium was injected manually.

Hemodynamic determinations: Left ventricular parameters were measured at spontaneous heart rate using the dual-tip micromanometer catheter, where $\geq 12$ heart beats were processed and averaged on-line by means of the representative beat method in a dedicated computer system. ${ }^{5,6}$ The following left ventricular pressure-derived indexes of isovolumic contraction and relaxation were computed: peak left ventricular pressure, end-diastolic pressure, peak first derivative of left ventricular pressure $(\mathrm{dP} / \mathrm{dt})$, peak left ventricular $\mathrm{dP} / \mathrm{dt} / \mathrm{p}$ from total pressurc providing $\mathrm{p}>20 \mathrm{~mm} \mathrm{Hg}$ (pcak $\left.\mathrm{V}_{\mathrm{CE}}\right), \mathrm{dP} / \mathrm{dt} / \mathrm{p}$ linearly extrapolated to $0 \mathrm{~mm} \mathrm{Hg}$ (Vmax), and the time constants for early relaxation (Tau), a semilogarithmic biexponential fit of the left ventricular pressure decay characterized by 2 exponential time constants: Tau1 for the first $40 \mathrm{~ms}$, and Tau2, the fit after the first $40 \mathrm{~ms}^{7}$ Mean aortic pressure was determined by digital integration.

Coronary venous blood flow measurements and calculations: Coronary sinus and great cardiac vein blood flows were measured on-line using a constant infusion thermodilution technique. Arterial, coronary sinus and great cardiac vein oxygen saturations were measured

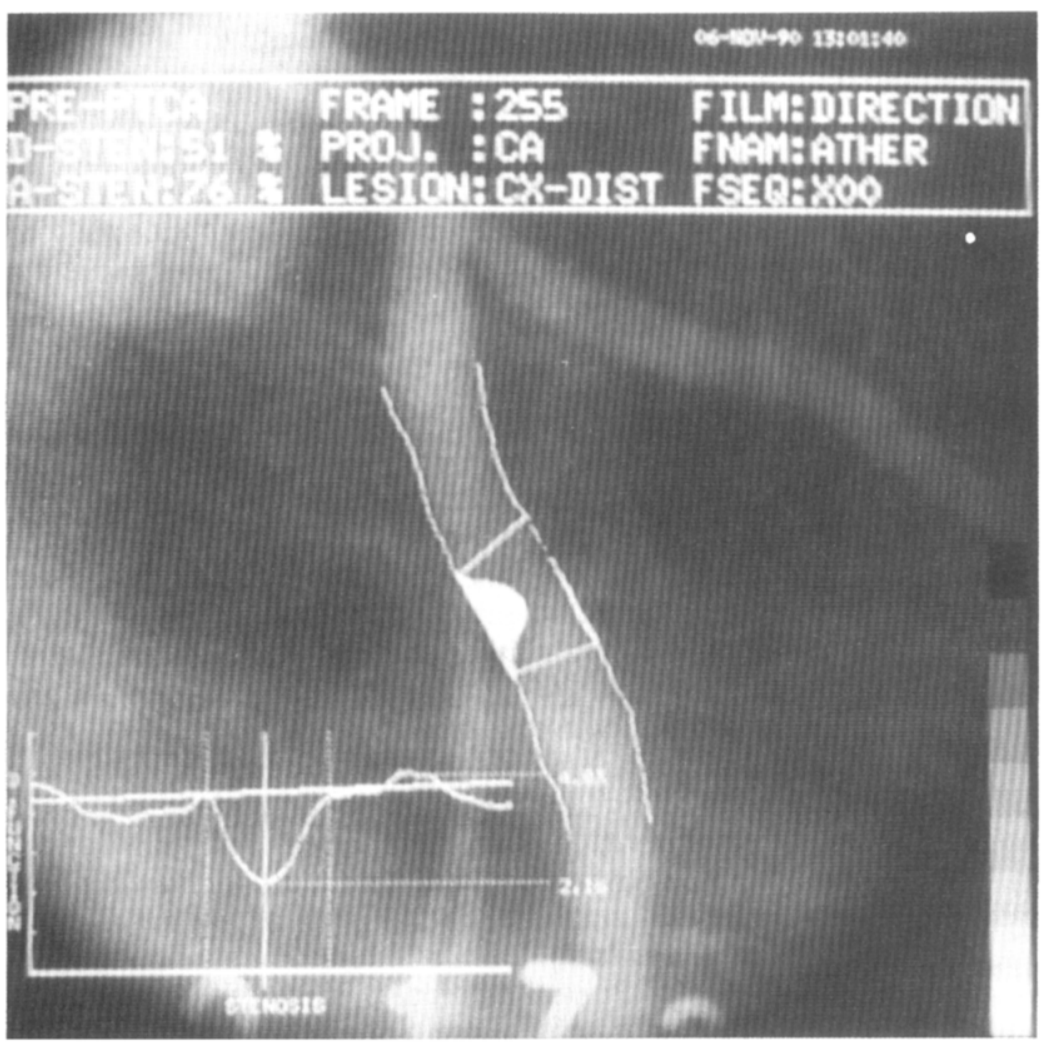

FIGURE 1. One cineframe of distal left circumilex (CX-DIST) coronary artery in caudal (CA) projection is shown with detected contours and diameter functions superimposed on original video image. On basis of proximal and distal segments, reference contours over obstructed region are reconstructed by interpolated diameter technique. Minimal obstruction and reference diameters are expresced in millimeters. In this case, reference diameter is $4.03 \mathrm{~mm}$, and obstruction diameter is 2.16 mm, corresponding to diameter stenosis (D-STEN) of $51 \%$, and area stenosis (A-STEN) of 76\%. PTCA = percutaneous transhuminal coronary angioplasty. 


\begin{tabular}{|c|c|c|c|c|c|}
\hline & Baseline & $\begin{array}{c}5 \\
\text { Minutes }\end{array}$ & $\begin{array}{c}10 \\
\text { Minutes }\end{array}$ & $\begin{array}{c}20 \\
\text { Minutes }\end{array}$ & $\begin{array}{c}30 \\
\text { Minutes }\end{array}$ \\
\hline Heart rate (beats/min) & $70 \pm 10$ & $73 \pm 11$ & $75 \pm 14$ & $73 \pm 18$ & $70 \pm 12$ \\
\hline Systolic aortic pressure $(\mathrm{mm} \mathrm{Hg})$ & $145 \pm 24$ & $130 \pm 24^{\star}$ & $123 \pm 22^{\star}$ & $140 \pm 32$ & $138 \pm 23$ \\
\hline Diastolic aortic pressure $(\mathrm{mm} \mathrm{Hg})$ & $70 \pm 9$ & $65 \pm 9 \ddagger$ & $61 \pm 8^{\star}$ & $69 \pm 15$ & $70 \pm 11$ \\
\hline Mean aortic pressure $(\mathrm{mm} \mathrm{Hg})$ & $98 \pm 15$ & $90 \pm 15^{*}$ & $86 \pm 14^{*}$ & $97 \pm 23$ & $97 \pm 14$ \\
\hline $\begin{array}{l}\text { Left ventricular systolic pressure } \\
\qquad(\mathrm{mm} \mathrm{Hg})\end{array}$ & $139 \pm 22$ & $126 \pm 22^{*}$ & $117 \pm 20^{*}$ & $133 \pm 29$ & $133 \pm 21 \dagger$ \\
\hline End-diastolic pressure $(\mathrm{mm} \mathrm{Hg})$ & $13 \pm 3$ & $12 \pm 4$ & $13 \pm 4$ & $13 \pm 4$ & $12 \pm 5$ \\
\hline Peak $V_{C E}\left(\mathrm{sec}^{-1}\right)$ & $39 \pm 9$ & $42 \pm 12$ & $42 \pm 13$ & $39 \pm 10$ & $39 \pm 9$ \\
\hline$V \max \left(\sec ^{-1}\right)$ & $56 \pm 10$ & $57 \pm 9$ & $60 \pm 10 \ddagger$ & $57 \pm 10$ & $54 \pm 9$ \\
\hline Positive $\mathrm{dP} / \mathrm{dt}(\mathrm{mm} \mathrm{Hg} \mathrm{sec}-1)$ & $1,485 \pm 308$ & $1,467 \pm 319$ & $1,496 \pm 396$ & $1,565 \pm 489$ & $1,453 \pm 308$ \\
\hline Negative $\mathrm{dP} / \mathrm{dt}\left(\mathrm{mm} \mathrm{Hg} \mathrm{sec}^{-1}\right)$ & $1,743 \pm 354$ & $1,673 \pm 350 \dagger$ & $1,637 \pm 359 \ddagger$ & $1,727 \pm 383$ & $1,712 \pm 358$ \\
\hline Taul (ms) & $49 \pm 11$ & $46 \pm 8 \dagger$ & $44 \pm 9 \dagger$ & $47 \pm 11$ & $48 \pm 11$ \\
\hline
\end{tabular}

spectrophotometrically, and oxygen content was calculated. Global (coronary sinus) and regional (great cardiac vein) myocardial oxygen consumptions were calculated as the product of coronary venous blood flow and arteriocoronary venous oxygen content difference. Global and regional coronary vascular resistances were derived from the ratio of mean aortic pressure to coronary venous flow.

Quantitative coronary angiography: Quantitative analysis of selected coronary segments was performed with the computer-assisted cardiovascular angiography analysis system that was described in detail previously. 8,9 Briefly, to analyze a coronary arterial segment in a selected frame of $35 \mathrm{~mm}$ cinefilm, an optically magnified portion of the image encompassing that segment is converted into video format by means of a cinevideo converter. The contours of the vessels are detected automatically on the basis of the weighted sum of first and second derivative functions applied to the digitized brightness information. Calibration of the diameter data of the vessels in absolute values ( $\mathrm{mm}$ ) is achieved using the angiographic catheter filmed empty of contrast. To this end, the contours of a user-defined portion of the optimally magnified catheter are detected automatically and corrected for pincushion distortion caused by the image intensifier. From the contours, vessel diameter functions (in absolute $\mathrm{mm}$ ) are determined by computing the shortest distances between the left and right contour positions. A representative analysis with the detected contours and diameter functions superimposed on the original video image is shown in Figure 1. For nonobstructed coronary segments, the mean diameter of the analyzed segment was computed. For obstructed segments, the minimal obstruction diameter was assessed. Average values for baseline, and 10- and 20-minute angiograms obtained from $\geq 2$ orthogonal angiographic views were compared.

Theoretical pressure gradient across stenotic lesions: For obstructed coronary segments, the theoretical pressure gradients across the stenotic lesion at theoretical coronary flow rates of 1,2 and $3 \mathrm{ml} / \mathrm{s}$ were calculated using the data obtained at quantitative angiographic analysis according to an accepted formula ${ }^{10,11}$ :
$\mathbf{P}_{\mathrm{GRAD}}=\mathrm{Q} \cdot\left(\mathrm{R}_{\mathrm{P}}+\mathrm{Q} \cdot \mathbf{R}_{\mathrm{T}}\right)$, where $\mathrm{P}_{\mathrm{GRAD}}$ is the theoretical pressure reduction $(\mathrm{mm} \mathrm{Hg}$ ) across the stenosis, $Q$ is the mean coronary blood flow $(\mathrm{ml} / \mathrm{s}), R_{P}$ is the Poiseuille resistance, and $R_{T}$ is the turbulent resistance. These resistances have been defined as follows:

$$
\mathrm{R}_{\mathrm{P}}=\mathrm{C}_{1} \times \frac{\text { (length obstruction) } \times \pi}{{\text { (obstruction area })^{2}}^{2}}
$$

where $C_{1}=8 \times$ (blood viscosity), with blood viscosity $=0.03(\mathrm{~g} / \mathrm{cm} \cdot \mathrm{s})$, and

$$
\mathrm{R}_{\mathrm{T}}=\mathrm{C}_{2} \times\left(\frac{1}{\text { obstruction area }}-\frac{1}{\text { normal distal area }}\right)^{2}
$$

where $\mathrm{C}_{2}=$ blood density $/ 0.266$, with blood density $=1.0\left(\mathrm{~g} / \mathrm{cm}^{3}\right)$. This assessment of pressure gradients was used and described in our previous studies. $12-14$

Statistical analysis: Results are expressed as mean \pm SD. The data was subjected to analysis of variance for repeated measurements, and when significant differences were apparent, further comparisons were made with Student's paired $t$ test. A p value $<0.05$ was considered significant.

\section{RESULTS}

Systemic hemodynamics: The systemic responses after intravenous administration of elgodipine at a rate of $1.5 \mu \mathrm{g} / \mathrm{kg} / \mathrm{min}$ over 10 minutes are listed in Table II. At spontaneous heart rate, elgodipine produced a significant decrease in aortic pressure, while heart rate did not change significantly. During elgodipine infusion, left ventricular systolic pressure decreased significantly by $16 \%$ ( $p<0.00005$ ), while end-diastolic pressure remained unchanged (Table II). Although the increase in peak $\mathrm{V}_{\mathrm{CE}}$ did not reach statistical significance, $\mathrm{V}_{\max }$ was significantly increased $(56 \pm 10$ to $60 \pm 10 \mathrm{sec}$ onds $\left.^{-1} ; \mathrm{p}<0.005\right)$, whereas Taul was shortened $(49 \pm$ 11 to $44 \pm 9 \mathrm{~ms} ; \mathrm{p}<0.05$ ). At 20 minutes, all parameters were no longer significantly different from baseline.

Coronary hemodynamics: After elgodipine infusion, coronary sinus and great cardiac vein blood flows increased significantly $(75 \pm 26$ to $86 \pm 30 \mathrm{ml} / \mathrm{min}[\mathrm{p}$ 


\begin{tabular}{|c|c|c|c|c|c|}
\hline & Baseline & $\begin{array}{c}5 \\
\text { Minutes }\end{array}$ & $\begin{array}{c}10 \\
\text { Minutes }\end{array}$ & $\begin{array}{c}20 \\
\text { Minutes }\end{array}$ & $\begin{array}{c}30 \\
\text { Minutes }\end{array}$ \\
\hline Coronary sinus flow ( $\mathrm{ml} / \mathrm{min})$ & $75 \pm 26$ & $81 \pm 30^{*}$ & $86 \pm 30 \dagger$ & $83 \pm 27 \ddagger$ & $81 \pm 28 \ddagger$ \\
\hline Great cardiac vein flow $(\mathrm{ml} / \mathrm{min})$ & $34 \pm 10$ & $38 \pm 13 \ddagger$ & $43 \pm 13^{*}$ & $39 \pm 12$ & $36 \pm 10$ \\
\hline Oxygen difference (aortocoronary sinus) (ml\%) & $13.9 \pm 1.7$ & $13.1 \pm 1.5^{\star}$ & $11.9 \pm 1.5 \S$ & $12.4 \pm 1.5^{\star}$ & $13.2 \pm 1.3^{*}$ \\
\hline Oxygen difference (aorta great cardiac vein) $(\mathrm{m} / \%)$ & $13.9 \pm 1.7$ & $13.2 \pm 1.5^{\star}$ & $12.0 \pm 1.5 \dagger$ & $12.5 \pm 1.1^{*}$ & $13.0 \pm 1.4^{*}$ \\
\hline Global myocardial oxygen consumption ( $\mathrm{ml} / \mathrm{min}$ ) & $10.2 \pm 3.0$ & $10.4 \pm 3.4$ & $10.1 \pm 3.3$ & $10.3 \pm 3.4$ & $10.5 \pm 3.3$ \\
\hline Regional myocardial oxygen consumption $(\mathrm{ml} / \mathrm{min})$ & $4.8 \pm 1.2$ & $5.1 \pm 1.5$ & $5.2 \pm 1.5$ & $5.1 \pm 1.6$ & $4.7 \pm 1.1$ \\
\hline Coronary sinus resistance $(\mathrm{mm} \mathrm{Hg} / \mathrm{ml} / \mathrm{min})$ & $1.5 \pm 0.5$ & $1.3 \pm 0.5 \dagger$ & $1.1 \pm 0.3 \S$ & $1.3 \pm 0.4 \ddagger$ & $1.3 \pm 0.5$ \\
\hline Great cardiac vein resistance $(\mathrm{mm} \mathrm{Hg} / \mathrm{m} / / \mathrm{min})$ & $3.2 \pm 1.4$ & $2.7 \pm 1.4^{\star}$ & $2.3 \pm 1.2 \dagger$ & $2.7 \pm 1.1 \ddagger$ & $3.0 \pm 1.3$ \\
\hline
\end{tabular}

\begin{tabular}{|c|c|c|c|c|c|}
\hline $\begin{array}{c}\text { Coronary } \\
\text { Artery Segment }\end{array}$ & Baseline & $\begin{array}{c}10 \\
\text { Minutes }\end{array}$ & $\begin{array}{c}p \\
\text { value* }\end{array}$ & $\begin{array}{c}30 \\
\text { Minutes }\end{array}$ & $\underset{\text { Value }^{*}}{\mathrm{p}}$ \\
\hline \multicolumn{6}{|c|}{ Left anterior descending } \\
\hline Proximal $(n=15)$ & $2.46 \pm 0.50$ & $2.69 \pm 0.50$ & 0.004 & $2.57 \pm 0.47$ & 0.06 \\
\hline $\operatorname{Mid}(n=11)$ & $2.53 \pm 0.58$ & $2.99 \pm 0.52$ & 0.05 & $2.67 \pm 0.52$ & 0.07 \\
\hline Distal $(n=14)$ & $1.81 \pm 0.27$ & $2.03 \pm 0.31$ & 0.03 & $1.93 \pm 0.28$ & 0.03 \\
\hline \multicolumn{6}{|l|}{ Left circumflex artery } \\
\hline Proximal $(n=15)$ & $2.51 \pm 0.51$ & $2.55 \pm 0.45$ & 0.1 & $2.64 \pm 0.48$ & 0.004 \\
\hline Distal $(n=14)$ & $2.06 \pm 0.38$ & $2.28 \pm 0.43$ & 0.0005 & $2.17 \pm 0.42$ & 0.04 \\
\hline Total $(n=69)$ & $2.27 \pm 0.53$ & $2.48 \pm 0.53$ & 0.000001 & $2.39 \pm 0.52$ & 0.000001 \\
\hline
\end{tabular}

\begin{tabular}{|c|c|c|c|c|c|}
\hline & Baseline & $\begin{array}{c}10 \\
\text { Minutes }\end{array}$ & $\underset{\text { Value}^{*}}{p}$ & $\begin{array}{c}30 \\
\text { Minutes }\end{array}$ & $\begin{array}{c}\rho \\
\text { Value* }\end{array}$ \\
\hline Obstruction length $(\mathrm{mm})$ & $5.09 \pm 2.12$ & $5.32 \pm 1.59$ & 0.9 & $4.77 \pm 1.25$ & 0.1 \\
\hline Obstruction diameter $(\mathrm{mm})$ & $1.08 \pm 0.29$ & $1.36 \pm 0.32$ & 0.02 & $1.26 \pm 0.33$ & 0.03 \\
\hline Obstruction area $\left(\mathrm{mm}^{2}\right)$ & $0.99 \pm 0.67$ & $1.56 \pm 0.84$ & 0.03 & $1.24 \pm 0.77$ & 0.09 \\
\hline Diameter stenosis (\%) & $58 \pm 6$ & $49 \pm 8$ & 0.008 & $52 \pm 10$ & 0.05 \\
\hline Area stenosis $(\%)$ & $85 \pm 9$ & $78 \pm 16$ & 0.08 & $83 \pm 13$ & 0.5 \\
\hline Reference diameter $(\mathrm{mm})$ & $2.51 \pm 0.52$ & $2.72 \pm 0.64$ & 0.09 & $2.63 \pm 0.44$ & 0.05 \\
\hline Reference area $\left(\mathrm{mm}^{2}\right)$ & $5.13 \pm 1.98$ & $6.11 \pm 2.69$ & 0.1 & $5.58 \pm 1.70$ & 0.08 \\
\hline Symmetry index & $0.64 \pm 0.18$ & $0.59 \pm 0.20$ & 0.9 & $0.56 \pm 0.22$ & 0.2 \\
\hline
\end{tabular}

$<0.0005$ ], and $34 \pm 10$ to $43 \pm 13 \mathrm{ml} / \mathrm{min}$ [p $<0.005$ ], respectively; Table III). As mean aortic pressure decreased from $98 \pm 15$ to $86 \pm 14 \mathrm{~mm} \mathrm{Hg} \mathrm{(p<}$ $0.00005)$, the calculated global and regional coronary vascular resistances decreased significantly $(1.5 \pm 0.5$ to $1.1 \pm 0.3 \mathrm{~mm} \mathrm{Hg} / \mathrm{ml} / \mathrm{min}$ [p <0.00005], and $3.2 \pm 1.4$ to $2.3 \pm 1.2 \mathrm{~mm} \mathrm{Hg} / \mathrm{ml} / \mathrm{min}$ [p $<0.0005$ ], respectively). Although the differences in mean arteriocoronary sinus and arterio-great cardiac vein oxygen contents decreased from $13.9 \pm 1.7$ to $11.9 \pm 1.5 \mathrm{ml} \%$ ( $p$ $<0.00005$ ) and from $13.9 \pm 1.7$ to $12.0 \pm 1.5 \mathrm{ml} \%$ (p $<0.0005$ ), respectively, the global and regional myocardial oxygen consumptions remained unchanged.

Quantitative coronary angiograms: In all, 69 coronary segments (including 13 stenotic segments) of the left coronary artery were analyzed. The individual changes in absolute diameter $(\mathrm{mm})$ of all coronary segments as measured during the 3 consecutive angiograms are listed in Table IV. Mean coronary diameter increased significantly from $2.27 \pm 0.53$ to $2.48 \pm$
$0.53 \mathrm{~mm}(\mathrm{p}<0.000001)$ at 10 minutes and to $2.39 \pm$ $0.52 \mathrm{~mm}(\mathrm{p}<0.000001)$ at 30 minutes after initiation of drug infusion.

Data for the 13 stenotic scgments are listed in Table V. Mean obstruction diameter increased significantly from $1.08 \pm 0.29$ to $1.36 \pm 0.32 \mathrm{~mm}(\mathrm{p}<0.02)$ at 10 minutes and to $1.26 \pm 0.33 \mathrm{~mm}(\mathrm{p}<0.03)$ at $30 \mathrm{~min}-$ utes after drug infusion was begun, whereas diameter stenosis decreased from $58 \pm 6$ to $49 \pm 8 \%$ ( $p<0.008$ ) and to $52 \pm 10 \%(\mathrm{p}<0.05)$, respectively. Consequently, assuming theoretical coronary flows of 1,2 and $3 \mathrm{ml} / \mathrm{s}$, the theoretical pressure gradients across the 13 stenotic lesions decreased significantly after elgodipine infusion (Figure 2).

\section{Discussion}

The results of this study of patients with coronary artery disease confirm for the first time the beneficial effects of elgodipine, a newly synthesized dihydropyridine calcium antagonist, on systemic and coronary he- 
modynamics previously suggested by animal experiments. 3,4

Effects on heart rate: Several studies in anesthetized animals ${ }^{3}$ showed that elgodipine is a potent systemic and coronary vasodilator, decreasing blood pressure and total peripheral resistance in a dose-dependent manner associated with an increase in coronary blood flow, whereas heart rate does not change or may even decrease in response to higher doses $(60 \mu \mathrm{g} / \mathrm{kg})$. Therefore, it is likely that (as observed with nimodipine) ${ }^{15}$ elgodipine possesses some negative chronotropic activity $^{1}$ that counteracts reflex tachycardia. However, it should be appreciated that reflex tachycardia can be attenuated by anesthetic agents, reducing this phenomenon in anesthetized animals. To establish the cardiovascular profile of elgodipine, free of the potential influence of anesthetic agents, van Woerkens et $\mathrm{al}^{4}$ investigated its effects in conscious instrumented pigs and observed a marked increase in heart rate, as well as in cardiac output and dP/dtmax. Although large doses of elgodipine were used, this may suggest that anesthesia in earlier studies blunted a reflex-mediated tachycardia. However, despite anesthesia, nisoldipine increases heart rate at a dose producing an equivalent reduction in systemic pressure. ${ }^{16}$ Furthermore, when elgodipine is administered to conscious pigs after $\beta$-adrenoceptor blockade with propranolol, positive chronotropic and inotropic effects are substantially reduced, although an increase in heart rate is not completely eliminated. ${ }^{4}$ This propranolol-resistant tachycardia is not unique to elgodipine, as it has also been observed for other dihydropyridines and vasodilators ${ }^{17-22}$ and suggests a withdrawal of parasympathic tone.

In the present study, despite a marked decrease in aortic pressure, only a slight increase in heart rate was observed and this did not reach statistical significance

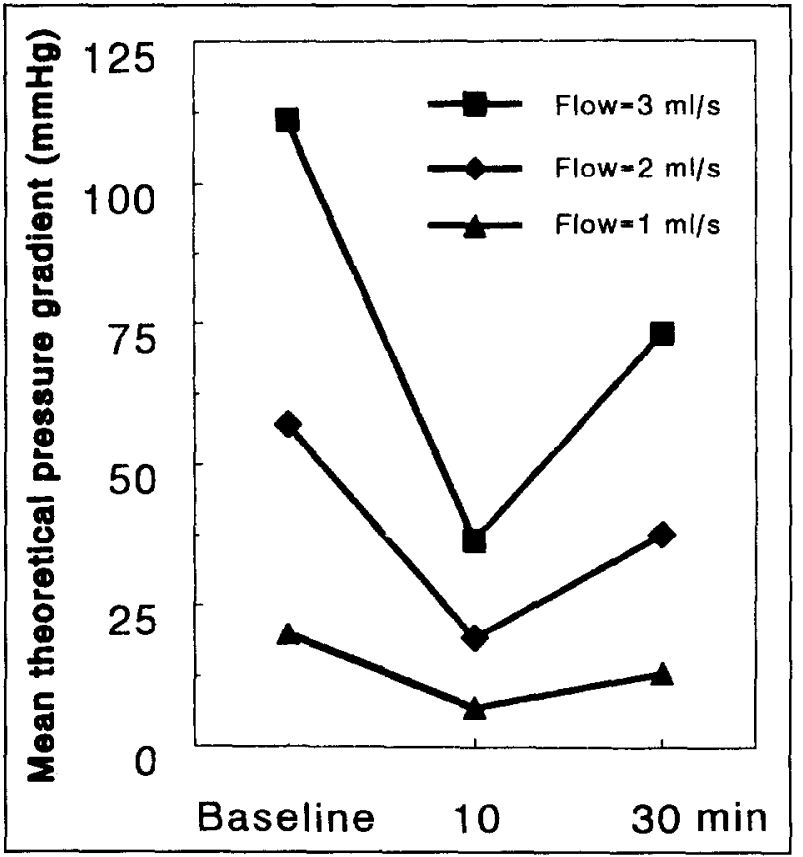

FICURE 2. Changes in mean theoretical presaure gradient across stenotic leaion at theoretical coronary flows of 1,2 and $3 \mathrm{ml} / \mathrm{s}$.

(Table II). Although all cardiac medication (including $\beta$-blocking agents) was discontinued in all patients $\geq 48$ hours before the study it may be speculated that $\beta$-adrenoceptor blockade could persist beyond this time and contributed to the lack of effect on heart rate. However, the resting heart rates of our study population suggest minimal $\beta$-blockade effect at the initiation of the study.

Effects on inotropic state: In vitro studies have shown that elgodipine appears to be 100 -fold more po-

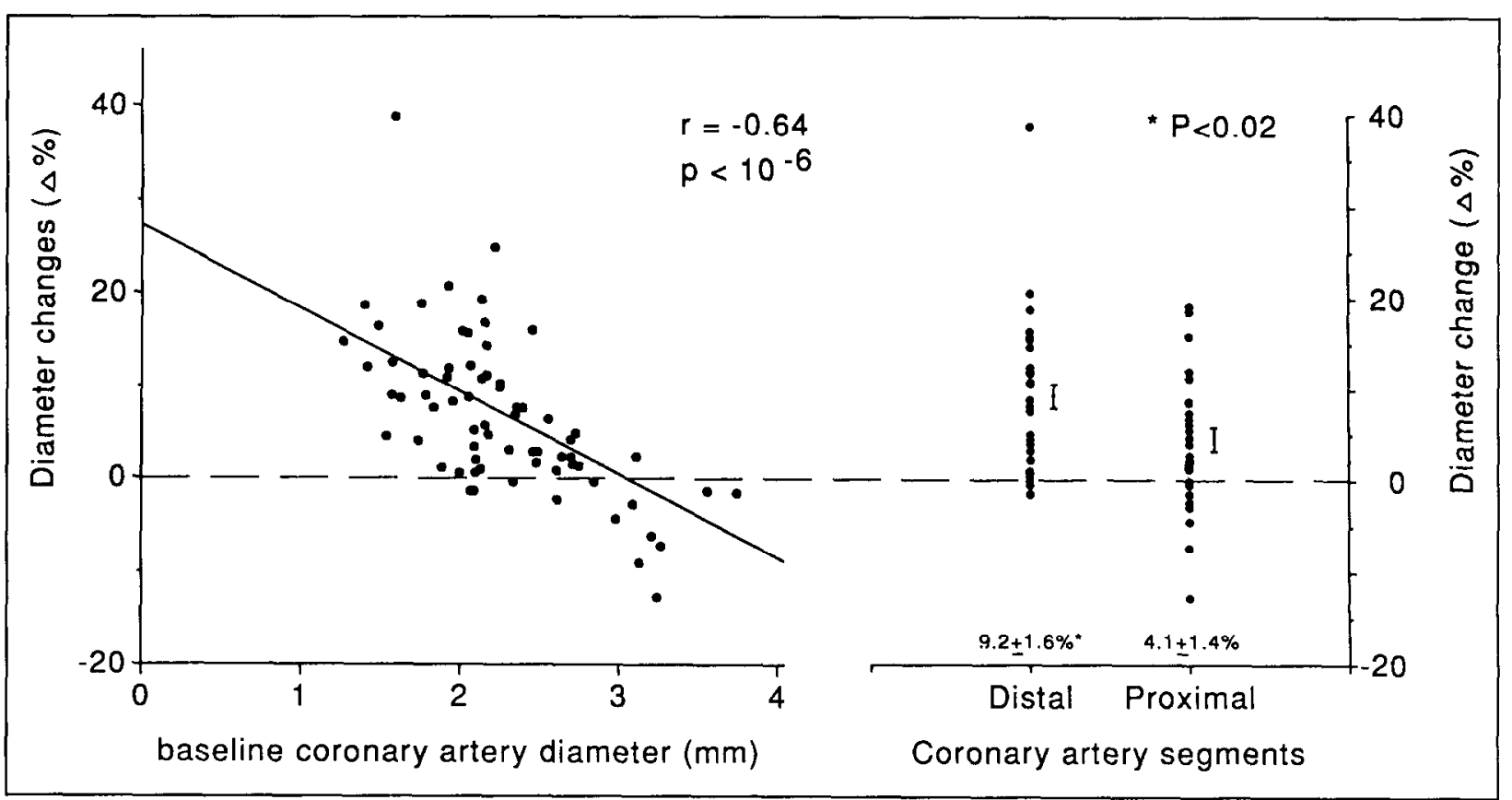

FIGURE 3. Left, diameter changes during elgodphe infusion (at 10 minutes) compared with baseline mean coronary artery ofameter. Right, diameter changes in proximal and distal parts of al anabyed coronary artery segments. 
tent as a vasodilator than as a negative inotrope. ${ }^{1}$ In conscious animals, elgodipine produces dose-related increases in cardiac output and $\mathrm{dP} / \mathrm{dtmax}$, while left ventricular end-diastolic pressure (as with other dihydropyridines) ${ }^{17}$ remains unchanged. ${ }^{4}$ In conscious pigs with a 3- to 4-week-old myocardial infarction, the vasodilator responses to elgodipine are similar, although accompanied by considerably less of an increase in $\mathrm{dP} / \mathrm{dtmax}$ compared with the effects in normal animals, but left ventricular end-diastolic pressure decreases significantly. ${ }^{4}$ In the present study, elgodipine infusion led to a slight but significant increase in Vmax (Table II). Because heart rate and left ventricular end-diastolic pressure were unaffected, it may be suggested that, as used in the present study, the compound does not exert negative inotropic actions. However, our approach using isovolumic indexes could not entirely exclude the possibility of some negative inotropism. Furthermore, because elgodipine does not possess any $\beta$-adrenomimetic effects, this relatively positive inotropic response to the drug is probably not an intrinsic property of this new calcium antagonist, but rather related to its ability to induce peripheral vasodilation and reduce impedance to left ventricular ejection.

However, the absence of a negative inotropic effect of elgodipine is even more evident during intracoronary infusion ${ }^{3} ; 0.3 \mu \mathrm{g} / \mathrm{kg} / \mathrm{min}$ substantially dilated the coronary vascular bed, but had only a minor effect on regional contractile function, whereas negative inotropic effects only became apparent at a rate of $0.9 \mu \mathrm{g} /$ $\mathrm{kg} / \mathrm{min}$, which also affected systemic responses. Administered intravenously, a 30-fold greater dose would be needed to produce a negative inotropic effect, almost 20 times the dose administered in our study. Realistically, such a dose would not be clinically appropriate, because of the likelihood of severe hypotension.

Effects on isovolumic relaxation: Experimental work has emphasized the role of calcium influx-efflux in regulating the relaxation of the myocardial cell. ${ }^{23}$ Left ventricular isovolumic relaxation is often abnormally prolonged in patients with coronary artery disease, ${ }^{7,24,25}$ probably due to the presence of fibrotic scar tissue or still viable myocardium in which the biochemical process of activation (contraction and relaxation) has been altered by chronic ischemia. ${ }^{25,26}$ Because it has been demonstrated that myocardial ischemia leads to asynergy of wall motion that can have a major role in altering the time course of the isovolumic pressure reduction, ${ }^{26,27}$ it may be expected that an improvement of the asynergic zones would result in a more synchronous and rapid relaxation of the whole ventricle. In our study, Tau 1 was significantly shortened after intravenous infusion of elgodipine (Table II). However, these results do not necessarily imply the intrinsic improvement of relaxation, but may be the indirect effects of a significant decrease in end-systolic pressure and volume.

Effects on coronary hemodynamics: Animal work has shown that intravenous elgodipine dose-dependently increases myocardial blood flow, with the greatest increase (up to $30 \%$ ) occurring in the subepicardial layer. ${ }^{3}$ In the presence of a simultaneous decrease in perfusion pressure, vasodilatation occurs in all layers of the myocardium to produce the necessary decrease in coronary vascular resistance, the decrease in the subepicardium (45\%) being more pronounced than that $(30 \%)$ in the subendocardium. ${ }^{3}$ The present study confirms that elgodipine is a potent coronary vasodilator in humans. Coronary sinus and great cardiac vein flows increased significantly during elgodipine infusion by 15 and $26 \%$, respectively. As mean aortic pressure dropped, substantial decreases in global $(-27 \%)$ and regional $(-28 \%)$ coronary vascular resistances were observed. The increase in coronary venous flow was associated with an increase in coronary venous oxygen saturation, resulting in a decrease in arteriocoronary venous oxygen content difference such that the calculated myocardial oxygen consumption did not decrease significantly (Table III). These results are consistent with our previous study of the effects of intravenous nisoldipine. ${ }^{28}$

Quantitative coronary angiography: To increase the accuracy of diameter measurements and to better reflect the true luminal cross-sectional area, multiple angiographic views ( $\geq 2$ orthogonal) were obtained in our study. If a coronary segment is nonaxisymmetric, vasodilation may accentuate the asymmetry of the lumen by preferentially relaxing the nonatherosclerotic part of the arterial wall. Consequently, the use of 1 angiographic view would be misleading. A relatively limited number of stenotic lesions was analyzed in this study owing to the following: (1) Selection needed high technical quality angiograms with clear views of the pre- and poststenotic segments; (2) orthogonal projections of the stenotic lesions were necessary; and (3) repeated angiography was limited to the left coronary artery.

Our results indicate that elgodipine induces significant vasodilatation not only in normal but also in stenotic coronary segments (Tables IV and V). The increase in the diameter of the nonstenotic segments was more pronounced in the distal and smaller sized segments than that in the larger proximal ones (Figure 3 ), as was previously observed with other vasodilatory agents. ${ }^{29,30}$ Furthermore, the theoretical pressure gradients across the stenotic lesions (computed from the data obtained at quantitative coronary angiography) showed a considerable decrease after elgodipine administration (Figure 2).

Clinical implications: At the dose used in the present study, elgodipine did not produce any untoward effects and was consistently beneficial in terms of coronary hemodynamics. Therefore, elgodipine is of potential value for the treatment of ischemic heart disease and hypertension. Furthcrmorc, the apparent absence of negative inotropic effects, and the reduction of cardiac afterload without an increase in preload are perhaps of particular relevance to the treatment of patients with mild to moderate congestive heart failure.

Acknowledgment: We thank the cardiac catheterization team of the Thoraxcenter, particularly Marjolein Wapenaar and Eline Montauban van Swijndregt, for professional assistance in the preparation of this manuscript. 


\section{REFERENCES}

1. Tejerina T, González P, Galiano A, Alguacil M, De Miguel B. Effects of elgodipine in vascular smooth muscle. Eur J Pharmacol 1990;183:552.

2. Román C, De Miguel B, Giráldez A, Galiano A. Study of agonism and antagonism of elgodipine on different types of receptors. Eur $J$ Pharmacol 1990;183:2411-2412.

3. Sassen LMA, Soei LK, Koning MMG, Verdouw PD. The central and regional cardiovascular responses to intravenous and intracoronary administration of the phenyldihydropyridine elgodipine in anaesthetized pigs. Br J Pharmacol 1990;99: 355-363.

4. van Woerkens LJ, Schotman SN, van der Giessen WJ, Verdouw PD. Cardiovascular effects of elgodipine in conscious pigs with a normal coronary circulation and in conscious pigs with a healed myocardial infarction. $J$ Cardiovasc Pharmacol 1991;17:976-982.

5. Meester GT, Zeelenberg C, Gorter S, Miller AC, Hugenholtz PG. Beat to beat analysis of left ventricular function parameters. Eur J Cardiol 1974;1:279-282. 6. Meester GT, Bernard N, Zeelenberg C, Brower R, Hugenholtz PG. A computer system for real time analysis of cardiac catheterization data. Cathet Cardiovasc Diagn 1975;1:113-132.

7. Brower RW, Meij S, Serruys PW. A model of asynchronous left ventricular relaxation predicting the bi-exponential pressure decay. Cardiovasc Res 1983; 17:482-488.

8. Reiber JHC, Serruys PW, Kooijman CJ, Wijns W, Slager CJ, Gerbrands JJ, Schuurbiers JCH, den Boer A, Hugenholtz PG. Assessment of short-, mediumand long-term variations in arterial dimensions from computed-assisted quantitation of coronary cineangiograms. Circulation 1985;71:280-288.

9. Serruys PW, Reiber JHC, Wijns W, van den Brand M, Kooijman CJ, ten Katen HJ, Hugenholtz PG. Assessment of percutaneous transluminal coronary angioplasty by quantitative coronary angiography: diameter versus densitometric area measurements. Am $J$ Cardiol 1984;54:482-488.

10. Brown BG, Bolson E, Frimer M, Dodge HT. Quantitative coronary arteriography. Estimation of dimensions, hemodynamic resistance and atheroma mass of coronary artery lesions using the arteriogram and digital computation. Circulation 1977;55:329-337.

11. Gould KL, Kelly KO, Bolson EL. Experimental validation of the quantitative coronary arteriography for determining pressure-flow characteristics of coronary stenosis. Circulation 1982;66:930-937.

12. Serruys PW, Juilliere Y, Bertrand M, Puel J, Rickards AF, Sigwart U. Additional improvement of stenosis geometry in human coronary arteries by stenting after balloon dilatation. Am J Cardiol 1988;61:71G-76G.

13. Zijlstra F, van Ommeren J, Reiber JHC, Serruys PW. Does quantitative assessment of coronary artery dimensions predict the physiologic significance of a coronary stenosis? Circulation 1987;75:1154-1161.

14. Suryapranata $\mathrm{H}$, Serruys $\mathrm{PW}$. Coronary vasodilatory action after nicorandil: a quantitative angiographic study. Am $J$ Cardiol 1989;63:80J-85J

15. Duncker DJ, Heiligers J, Mylecharane EJ, Saxena PR, Verdouw PD. Nimodipine-induced changes in the distribution of carotid blood flow and cardiac output in pentobarbital-anaesthetized pigs. Br $J$ Pharmacol 1986;89:35-46.

16. Duncker DJ, Hartog JM, Hugenholtz PG, Saxena PR, Verdouw PD. The effects of nisoldipine (Bay K 5552) on cardiovascular performance and regional blood flow in pentobarbital-anaesthetized pigs with or without beta-adrenoceptor blockade. $\mathrm{Br} J$ Pharmacol 1986;88:9-18.

17. Duncker DJ, Saxena PR, Verdouw PD. Systemic haemodynamics of dihydropyridine derivatives in conscious pigs with or without propranolol. Eur J Pharmacol 1988;156:401-409.

18. Man in't Veld AJ, Wenting GJ, Verhoeven RP, Schalekamp MADH. Sympathetic and parasympathetic components of cardiostimulation during vasodilator treatment of hypertension. Clin Sci Mol Med 1978;55:329S-332S.

19. Reid JL. Acutc and chronic beta-receptor blockade with propranolol and the cardiovascular response to intravenous sodium nitroprusside in the conscious rabbit. J Cardiovasc Pharmacol 1979;1:403-414.

20. Nakaya H, Schwartz A, Millard RW. Reflex chronotropic and inotropic effects of calcium channel-blocking agents in conscious dogs. Diltiazem, verapamil and nifedipine compared. Circ Res 1983;52:303-311.

21. Bolt GR, Saxena PR. Interaction of atenolol with the systemic and regiona hemodynamic effects of hydralazine in conscious renal hypertensive rabbits. $J$ Pharmacol Exp Ther 1984;230:205-213.

22. Warltier DC, Zyvoloski MG, Gross GJ, Brooks HL. Comparative actions of dihydropyridine slow channel calcium blocking agents in conscious dugs: systemic and coronary hemodynamics with and without combined beta-adrenergic blockade. J Pharmacol Exp Ther 1984;230:367-375.

23. Lorrell BH, Barry WH. Effects of verapamil on contraction and relaxation of cultured chick embryo ventricular cells during calcium overload. $J$ Am Coll Cardiol 1984:3:341-348.

24. Serruys PW, Wijns W, van den Brand M, Meij S, Slager CJ, Schuurbiers JHC, Hugenholtz PG, Brower RW. Left ventricular performance, regional blood flow, wall motion and lactate metabolism during transluminal angioplasty. Circulation 1984:70:25-36.

25. Pouleur H, Rousseau MF, van Eyll V, Charlier AA. Assessment of regional left ventricular relaxation in patients with coronary artery disease: importance of geometric factors and change in wall thickness. Circulation 1984;69:696-702 26. Papapietro SE, Coghlan HC, Zissermann D, Russell RO, Rackley CE Rogers WJ. Impaired maximal rate of left ventricular relaxation in patients with coronary artery disease and left ventricular dysfunction. Circulation 1979;59: 984-991.

27. Rousseau M, Veriter C, Detry JMR, Brasseur L, Pouleur H. Impaired early left ventricular relaxation in coronary artery disease: effects of intracoronary nifedipine. Circulation 1980;62:764-772.

28. Serruys PW, Suryapranata H, Planellas J, Wijns W, Vanhaleweijk G, Jaski BE, Hugenholtz PG. Effects of short-term intravenous administration of nisoldipine on left ventricular and coronary hemodynamics in patients with coronary artcry discase. Am J Cardiol 1985;56:140-146.

29. Schulz W, Wendt T, Scherer D, Kober G. Diameter changes of epicardial coronary arteries and coronary stenoses after intracoronary application of $\mathrm{Sin} 1$, a molsidomine metabolite. 7. Kardiol 1983;72:404-409.

30. Suryapranata H, Serruys PW, de Feyter PJ, Verdouw PD, Hugenholtz PG Coronary vasodilatory action after a single dose of nicorandil. Am J Cardiol 1988;61:292-297. 